\title{
MULTIPLE MYELOMA PRESENTING AS SMALL VESSEL VASCULITIS IN A PATIENT WITH NO CRYOGLOBULINEMIA: CASE REPORT
}

Túlio Silva Freire ${ }^{1}$, Villane Matheus Fernandes Silva ${ }^{1}$, Raquel Anne Bacurau Monteiro², Hugo Deleon de Lima ${ }^{2 \star}$, Guilherme Augusto Silva ${ }^{2}$, Gabriella Seixas Doca Cortez ${ }^{2}$, Amanda Queiroz da Mota Silveira Aroucha², Henrique Ataide Mariz ${ }^{2}$, Renan Mesel Correia², Laurindo Ferreira da Rocha Junior ${ }^{1,2}$

1.Centro Universitário Unifacisa, Campina Grande (PB), Brazil. 2. Instituto de Medicina Integral Professor Fernando Figueira, Recife (PE), Brazil.

*Corresponding author: hugodeleondelima@gmail.com

\section{BACKGROUND}

Multiple myeloma (MM) is typically characterized by the neoplastic proliferation of plasma cells producing a monoclonal immunoglobulin. Most patients with MM present with signs or symptoms related to the infiltration of plasma cells into the bone or other organs or to kidney damage from immunoglobulin deposition. Skin involvement is rarely found in this disorder. There are reports of vasculitic cutaneous lesions associated with MM mostly due to cryoglobulinemic vasculitis. We report a case of multiple myeloma presenting as a small vessel vasculitis in a patient with no cryoglobulinemia and no other clinical feature of the disease.

\section{CASE REPORT}

An 80-year-old female patient was referred to our outpatient rheumatology clinic with history of pain in the fingers of both hands associated with vasculitic lesions that started one year before. She had also history of weight loss during this period (13 kg). Physical examination revealed small vasculitic cutaneous lesions in the extremity of fingers of both hands. Initial laboratory tests were hemoglobin $11.5 \mathrm{~g} / \mathrm{dL}$, leukocytes 21,400 (mm3), neutrophils $45 \%$, platelets 229,000 (mm3), creatinine $0.7 \mathrm{mg} / \mathrm{dL}$, urea $45 \mathrm{mg} / \mathrm{dL}$, ESR $8 \mathrm{~mm} / \mathrm{h}$, ferritin $519 \mathrm{ng} / \mathrm{mL}$, calcium $9.2 \mathrm{mg} / \mathrm{dL}$. Serology for HIV, syphilis, hepatitis B and C were negative. Serum rheumatoid factor, ANA and cryoglobulins were also negative. Serum tumor markers (alpha-fetoprotein, CA 125, CA 19.9, CEA, CA15.3) were within normal range. Serum protein electrophoresis displayed monoclonal gammopathy. Immunoelectrophoresis demonstrated the presence of the monoclonal band IgG Kappa. As multiple myeloma was the diagnostic hypothesis, the patient underwent bone marrow aspiration that showed $12 \%$ of plasma cells. Plain radiographs of bones showed no osteolytic lesions. The patient underwent chemotherapy (bortezomib, cyclophosphamide and dexamethasone) and, after the 4th cycle, a new bone marrow aspiration was performed, but no plasma cells were found and the vasculitic cutaneous lesions had complete resolution.

\section{CONCLUSION}

We present a case of vasculitis of fingers in a patient with multiple myeloma without the classical clinical features, such as kidney or bone injury and negative for the presence of serum cryoglobulins. Small vasculitic cutaneous lesions may be the initial clinical feature of multiple myeloma and this malignancy must be suspected even in the absence of typical findings particularly in elderly patients. 